\title{
Research on User-side Big Data and Parallel Network Prediction Based on Cloud Computing Platform
}

\author{
Haoying Chen \\ Kunming University of Science and Technology Oxbrioge College, Kunming, Yunnan, China
}

Keywords: Cloud computing, Big data, Network forecasting

\begin{abstract}
With the rapid development of Internet technology, computers are gradually changing people's way of production, life and work. In the process of computer popularization, data processing capabilities become important, so this requires relevant workers to take strong measures to ensure the speed and quality of computer processing data, analysis for the development of various industries are important the impact of the. In the era of large data, enterprises can dig through the analysis and analysis of data out of the enterprise decision-making or development of the meaning of the data, this kind of can be enough to push Further development of the business. When, big data analytics and cloud computing network technology have their own excellent The trend and the inferior situation, the need for each enterprise root according to their own actual situation To choose the data management method for the choice of phase.
\end{abstract}

\section{Introduction}

With the rapid development of computer technology, the importance of computing and processing huge amounts of data is becoming more and more prominent. The advantages of big data analysis technology in computing are visual analysis, data mining algorithm, predictive analysis, semantic engine, data quality and data management. Cloud computing technologies include major technologies such as virtualization, distributed storage, distributed computing, and multi-tenancy. In modern society, a socially recognized data processing technology includes at least three characteristics: data analysis timeliness, data security encryption and strong computing power. In view of this kind of situation, the author analyzes the big data of computer, discusses and analyzes the network technology of cloud computing, in order to provide reference and reference for the future development of computer [1].

\section{Definition of Big Data and Cloud Computing}

Big Data: Big Data is a collection of data that cannot be captured, managed, and processed with conventional software tools within a certain time frame, requiring new processing models to be a massive, high-growth, and diverse information asset with greater decision-making, insight discovery, and process optimization capabilities [2].

Cloud computing: Cloud computing is the product of the evolution of traditional computer and network technologies such as distributed computing, parallel computing, utility computing, network storage, virtualization, load balancing, and thermal backup redundancy. Table 1 is cloud computing service type [3].

Table 1 Types of Cloud Computing Services

\begin{tabular}{|l|l|}
\hline Type & Content \\
\hline $\begin{array}{l}\text { Infrastructure as a } \\
\text { Service (IAAS) }\end{array}$ & $\begin{array}{l}\text { Infrastructure as a service is one of the main service categories that providevirtual computing } \\
\text { resources such as virtualized computing resources, such as virtual machines, storage, } \\
\text { networks, and operating systems, to individuals or organizations of cloud computing } \\
\text { providers. }\end{array}$ \\
\hline $\begin{array}{l}\text { Platforms and } \\
\text { services(PAAS) }\end{array}$ & $\begin{array}{l}\text { Platform as a Service is a service category that provides developers with a platform to build } \\
\text { applications and services over the global Internet. Paas provides an on-demand development } \\
\text { environment for developing, testing, and managing software applications. }\end{array}$ \\
\hline
\end{tabular}




\begin{tabular}{ll|l}
$\begin{array}{l}\text { Software as a } \\
\text { Service(SAAS) }\end{array}$ & $\begin{array}{l}\text { Software-as-a-Service is also a category of its services, offering pay-as-you-go software } \\
\text { applications over the Internet, cloud computing providers hosting and managing software } \\
\text { applications and allowing their users to connect to applications and access applications over } \\
\text { the global Internet. }\end{array}$
\end{tabular}

\section{Benefits of Big Data Analytics}

\subsection{Visual Analysis}

Visual analysis, which provides a very intuitive and clear representation of the structure and characteristics of the data [4].

\subsection{Data Digging Algorithm}

For the development of the present generation of society, big data analysis is a key subject , while the data digging algorithm is more of the core in it. For different data classes, you need to use different data algorithms. If this is the case, it will be enough to make data analysis more scientific, more accurate Suddenly the unique point of the data body. Through this algorithm, it is sufficient to make the data analysis more valuable [5].

\subsection{Pre-Measured Analysis}

As the hot point of the present era, the big data is familiar to people know, while the large data pre-test is more of the hot door in it. Because in many domains, you can apply big data analytics pretests. Example, enterprise root based on data to pre-measure the development trend of their own, root according to The market line to predict the market direction after today, etc. Don't look at it from the quality of the data, it's also the tube from the data "To analyze, it is all a high-value evaluation criteria." And big data analytics is closely related to the quality and management of data, If the analytical quality of the data is higher, it will be willing to bring more High-efficiency data management, which is essential for the development of any industry There is a sense of importance, in order to ensure that the results obtained by data analysis are True [6].

\subsection{Semantic Engine}

Semantic engine, need enough science and technology, actively analyze data and extract relevant information [7].

\subsection{Data Quality and Data Management}

Big data analytics is closely related to data management and data quality, high-quality data and efficient management, whether in academic research or commercial applications, to ensure the effectiveness and authenticity of its analysis results [8].

\section{Disadvantages of Big Data Analytics}

(1) While big data has great potential for growth, some privacy groups are starting to move, because more and more data is being collected, regardless of whether it is intentional or unintentional, some data has spread through social media, in a state of disarray to reveal some of the digital details of their daily lives. The number of trades, or the number of people in the privacy category And so the people gathered up, will certainly affect people's daily activities . No matter the data collection is mind-set or unintentional, there is some data will pass through a little flat taiwan spread out to go, this kind of lead to people's hidden Private being revealed to go out, will give people a definite impact on their lives [9].

(2) Because of the huge collection of data, the relevant predictions made on this basis may result in false information that directly leads to a deviation from the expected decision. In addition, the use of data people are also divided into good and evil, data on the role of things are also good or bad, is a double-edged sword [10]. 


\section{Benefits of Cloud Computing Technology}

(1) Reduce computer costs: No hard disk space or processing power required for traditional software, all applications are running in the cloud.

(2) Improved performance: Computers in cloud computing systems are more efficient because there are fewer programs and processes.

(3) Almost unlimited storage capacity: Since it's a computer in the cloud, it's not to mention storage capacity.

(4) Stored data is secure: Since all data is stored in the cloud, there is no need to worry about data loss.

\section{Weaknesses in Cloud Computing Technology}

(1) Cloud computing networks are not effective lying to the security of user data. When an organization chooses to store data or host applications on a public cloud, it loses the ability to physically access the servers that host its information. As a result, unauthorized users can also access relevant data through certain means.

(2) Cloud computing network virtualization has a security risk. Operating system and bottom hardware due to virtualization technology, the relationship between the two has changed greatly, resulting in storage and computing, and even network changes. The use of virtualization in the cloud base has created a corresponding security risk for consumers.

\section{Conclusion}

With the development of computer technology and communication technology, computer network has become the most important means of information exchange among various media. However, communication is often accompanied by a huge amount of data, will penetrate all areas and classes of the world. Therefore, big data analytics and the development of cloud computing networks will become very important for the entire information field.

\section{References}

[1] Li Zhen (2020). Research on computer big data analysis and cloud computing network technology. Science and Technology Innovation and Application, no.02, pp. 150-151.

[2] Zhao Dongmei (2019). Research on Construction of Cloud Computing-based Accounting Big Data Analysis Platform. Finance and Accounting Study, no.35, pp. 4-6.

[3] Luo Xinman (2019). Application of Big Data Technology in Computer Network Information Management. Electronic Technology and Software Engineering, no.20, pp. 150-151.

[4] In-depth interpretation of industrial big data.Software and Integrated Circuits, no.09:pp. 83-87.

[5] Guo Hairong (2019). Nonlinear prediction modeling of network traffic in big data environment. Microcomputer Applications, Vol.35,no.08, pp. 149-151.

[6] Yu Xiao, Han Qi (2019). Computer big data analysis and cloud computing network technology. Electronic Technology and Software Engineering, no.09, pp. 154.

[7] Yin Qilong, Wang Junce (2019). Talking about Computer Big Data Analysis and Cloud Computing Network Technology. Information and Computer (Theoretical Edition), no.17, pp. 121123.

[8] Hua Li, Chen Cheng (2017). Application of Meteorological Big Data Service in Cloud Computing Environment. Agriculture and Technology, Vol.37,no.20, pp. $231+234$.

[9] Shi Weisong, Sun Hui, Cao Jie, Zhang Quan, Liu Wei (2017). Edge Computing: A New Computing Model in the Era of Everything. Journal of Computer Research and 
Development,Vol.54,no.05, pp. 907-924.

[10] Liu Jie (2016). Innovative application and development trend of big data. Communication Management and Technology, no.05, pp. 28-31.

[11] Chen Chen (2016). Construction of library big data analysis and decision support platform based on cloud computing .Library Theory and Practice, no.05, pp. 101-104. 